\title{
Recommended Scoring Approach for the Pediatric Patient-Reported Outcomes version of the Common Terminology Criteria for Adverse Events
}

\author{
Pamela Hinds ${ }^{1}$, Laura Pinheiro ${ }^{2}$, Molly McFatrich ${ }^{3}$, Mia Waldron ${ }^{4}$, Justin Baker ${ }^{5}$, \\ Catriona Mowbray ${ }^{1}$, Scott Maurer ${ }^{6}$, Yao Cheng ${ }^{1}$, Bryce Reeve ${ }^{3}$, and Jichuan Wang ${ }^{1}$ \\ ${ }^{1}$ Children's National Medical Center \\ ${ }^{2}$ Well Cornell Medicine \\ ${ }^{3}$ Duke University School of Medicine \\ ${ }^{4}$ Childrenś National Health System \\ ${ }^{5}$ St. Jude Children's Research Hospital \\ ${ }^{6}$ Children's Hospital of Pittsburgh of UPMC
}

September 25, 2021

\begin{abstract}
Background Collecting symptom, function and adverse event (AE) data directly from children and adolescents undergoing cancer care is more comprehensive and accurate than relying solely on their caregivers or clinicians for their interpretations. We developed the Pediatric Patient-Reported Outcomes version of the Common Terminology Criteria for Adverse Events (PedPRO-CTCAE) measurement system with input from children, parents, and clinicians. Here we report how we determined the recommended Ped-PRO-CTCAE item scoring approach. Methods Scoring approaches compared were 1) at the AE attribute (frequency, severity, interference) using ordinal and dichotomous measures, 2) a weighted composite AE item score by AE attribute (0.5 - frequency; 1.0 - severity; 1.5 - interference), and 3) overall number of AEs endorsed. Associations of each

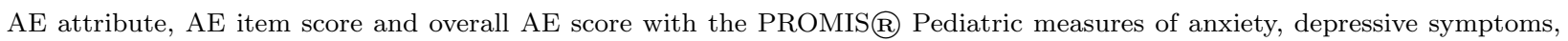
and fatigue were examined. The ability of the overall Ped-Pro-CTCAE AE score to identify patients with PROMIS symptom T-scores worse than reference population scores was assessed. Clinician preference for score information display was elicited through interviews. Results The diverse scoring approaches yielded similar outcomes, including positive correlations of the PedPRO-CTCAE attributes, AE item score, and the overall AEs score with the PROMIS Pediatric measures. Clinicians preferred the most granular display of scoring information (actual score reported by the child and corresponding descriptive term). Conclusions Although three scoring approaches yielded similar results, we recommend the AE attribute level of one score per Ped-Pro-CTCAE AE attribute for its simplicity of use in clinical care and research.
\end{abstract}

\section{Hosted file}

Scoring Manuscript-09-02-21.docx available at https://authorea.com/users/437388/articles/ 539057-recommended-scoring-approach-for-the-pediatric-patient-reported-outcomes-versionof-the-common-terminology-criteria-for-adverse-events

\section{Hosted file}

Scoring Manuscript Table 1 Sample Characteristics.docx available at https://authorea.com/ users/437388/articles/539057-recommended-scoring-approach-for-the-pediatric-patientreported-outcomes-version-of-the-common-terminology-criteria-for-adverse-events 


\section{Hosted file}

Scoring Manuscript Table 2 Polyserial Correlations of Ped-PRO-CTCAE Symptomatic AEs wtih PROMIS Pediatr available at https://authorea.com/users/437388/articles/539057-recommended-scoring-approachfor-the-pediatric-patient-reported-outcomes-version-of-the-common-terminology-criteriafor-adverse-events

\section{Hosted file}

Scoring Manuscript Table 3 Biserial Correlations of Ped-PRO-CTCAE Symptomatic AE Dichotomous Items with available at https://authorea.com/users/437388/articles/539057-recommended-scoring-approachfor-the-pediatric-patient-reported-outcomes-version-of-the-common-terminology-criteriafor-adverse-events

\section{Hosted file}

Scoring Manuscript Table 4 Spearman Correlations of Weighted AE Scores with PROMIS Pediatric Measures . available at https://authorea.com/users/437388/articles/539057-recommended-scoring-approachfor-the-pediatric-patient-reported-outcomes-version-of-the-common-terminology-criteriafor-adverse-events

\section{Hosted file}

Scoring Manuscript Table 5 Cut-off Point for the Ped-PRO-CTCAE Overall Scores to Predict PROMIS Pediatr available at https://authorea.com/users/437388/articles/539057-recommended-scoring-approachfor-the-pediatric-patient-reported-outcomes-version-of-the-common-terminology-criteriafor-adverse-events 